\title{
US proposes exemptions from DNA guidelines
}

CerTAIN experiments using recombinant DNA techniques will be exempted from regulatory guidelines, according to proposals published in Washington last week, and the physical and biological containment requirements for a number of experiments will be lowered. These recommendations come in the light of revised estimates about the danger of experiments using disabled host-vector systems. The proposals also suggest that public representatives should be included on local biosafety committees.

The revisions have been prepared by Dr Donald Fredrickson, dircctor of the National Institutes of Health, following lengthy discussion of the present guidelines which have been in force since June 1976. The new guidelines would cover all research carried out by institutions receiving NIII funds for recombinant DNA research, not merely that which is supported by NIH.

The guidelines were published in the Federal Register by the Department of Health, Education and Welfare on 28 July, and will be open for public discussion for 60 days. This includes a public hearing next month before a departmental review committee chaired by the department's general counsel, Mr Peter Libassi.

Health Secretary Mr Joseph A. Califano has asked in particular for comments on proposed mechanisms for administering and further revising the guidelines. After the public discussion, the final version of the guidelines will be prepared by Dr Fredrickson and promulgated within 45 days.

In an introduction to the proposed revisions, Dr Fredrickson says it is five years since concern arose about the possible hazards of laboratory experiments using recombinant DNA techniques. During this period no evidence has come to light of a product created by these techniques that has been harmful to man or the environment. "At the very least, there is growing sentiment that the burden of proof is shifting towards those who would restrict recombinant DNA research," Dr Fredrickson says.

Increased confidence about the use of modified host-vector systems has led to a recommendation for changes in required containment levels for certain types of experiments. For example, shotgun experiments involving birds and mammals other than primates, originally requiring $\mathrm{P} 4$ /EK2 or $\mathrm{P} 3 / \mathrm{EK} 3$ containment in the 1976 guidelines, would now require only $\mathrm{P} 2 / \mathrm{EK} 2$.

One aspect of the proposed revisions that seems destined to be a target of controversy is the proposal to exempt entirely from the guidelines certain

\section{'The burden of proof is shifting towards those who would restrict recombinant DNA research' \\ -Dr Donald Fredrickson}

categories of experiments. These categories cover experiments using:

- "naked" recombinant DNA molecules which are not in organisms or viruses, and which are considered "extremely unlikely to be hazardous under experimental conditions";

- recombinant DNA molecules which consist entirely of DNA segments from a single non-chromosomal or viral source;

- recombinant DNA molecules made entirely from the DNA of a single organism, including the plasmids, viruses, mitochondria or chloroplasts indigenous to that organism, when propagated only in that organism;

- certain specified recombinant DNA molecules that consist entirely of DNA segments from different species that exchange DNA by known physiological processes. A list of such species would be prepared and periodically revised by the director of NIH (see below);

- any other classes of recombinant DNA molecules which the director of $\mathrm{NIH}$, on the recommendation of his advisory committee, considers "do not present a significant risk to health or the environment".

The proposed guidelines offer a revised definition of recombinant DNA molecules as being either molecules which are constructed outside living cells by joining natural or synthetic DNA segments to DNA molecules that can replicate in a living cell, or DNA molecules that result from the replication of such molecules.

One major change is the decision to lift a previous ban on the use of

\section{Proposed exemptions}

Any recombinant DNA molecules to be propagated in species listed here, if the DNA is composed entirely of DNA segments from the same list of organisms, are exempted from control. This exemption acknowledges that these bacteria exchange DNA in nature.

\section{Escherichia species}

Edwardsiella species

Citrobacter species (including Levinea)

Salmonella species (including Arizona)

Shigella species

Klebsiella species

Enterobacter species

Hafnia species

Serratia species

Erwinia species (including Pectobacterium)

Pseudomonas species

Rhi-obium species

Acinetobacter calcoaceticus

Agrobacterium tumefaciens

Rhodopseudomonas sphaeroides
Vesicular Stomatitis Virus (VSV) and of oncogenic viruses classified by the National Cancer Institute as "moderate risk", and to allow such experiments under specified conditions.

Dr Fredrickson's reasoning behind this is that recombinant DNA experiments with pieces of these viruses cloned in $E$ coli $\mathrm{K}-12$ pose no more risk, and actually appear to pose less risk, than work with the whole infectious virus itself.

With regard to physical containment levels, in addition to introducing a measure of flexibility in the choice of containment equipment, Dr Fredrickson also proposes that pipetting by mouth, already prohibited in categories P2, P3 and P4, should also be prohibited in category $\mathrm{Pl}$.

Suggestions are made about the activities of local biosafety review committees (re-named from local biohazard committees). For example, although NIH approval would still be required before new recombinant DNA experiments could go ahead, the local committee could approve subsequent extensions.

In view of the increased responsibility of such committees, Dr Fredrickson suggests adding a provision that "no LBC may consist entirely of persons who are officers, employecs or agents of, or are otherwise associated with, the institution, apart from their membership of the LBC."'

Other requirements for membership are not laid down, although the proposals suggest that "membership should include individuals from disciplines relevant to recombinant DNA technology, biological safety and engineering"; that "at least one member be a non-doctoral individual from a laboratогу technical staff"; and that the LBC include "members knowledgeable about such matters as applicable law, standards of professional conduct and practice, community attitudes, and the environment".

The new proposals also enable the private sector to register voluntarily its recombinant DNA activities with the NIH. Other services, including consulting services and the certification of host-vector systems, would be provided, and the service would be accompanied by protection of proprietary data.

Finally Dr Fredrickson says that "while it is true that other techniques in genetic research, such as cell fusion and chromosome transfer, may result in the formation of recombinant molecules. I do not believe at this time we should mandate or extend the guidelines to research in these areas."

David Dickson 